\title{
Farmakoterapija
}

\section{Triguba terapija gydant LOPL. Klinikinių tyrimų apžvalga}

\author{
TRIPLE THERAPY IN COPD: REVIEW OF CLINICAL TRIALS
}

\author{
JOLITA PALAČIONYTÉ \\ LSMU MA Pulmonologijos klinika
}

\begin{abstract}
Santrauka. Pastaraisiais metais patvirtinti du trijų veikliujų medžiagų viename inhaliatoriuje vaistų deriniai sergantiesiems lètine obstrukcine plaučių liga (LOPL). Abu vaistų derinius sudaro įkvepiamieji gliukokortikoidai (iGK), ilgo veikimo $\beta_{2}$ agonistai (IVBA) ir ilgo veikimo muskarino receptorių blokatoriai (IVMB). Šioje apžvalgoje pateikiami klinikinių tyrimų duomenys apie trigubos terapijos veiksmingumą ir saugumą gydant LOPL. Trijuose iš penkių iki šiol atliktų klinikinių tyrimų (TRILOGY, TRINITY ir TRIBUTE) sergantiesiems LOPL skirtas gydymas beklometazono dipropionato, formoterolio fumarato ir glikopironiumo (BDF/FF/G) deriniu, dviejuose (FULFIL ir IMPACT): flutikazono furoato, vilanterolio ir umeklidino (FLF/VI/UMEC) deriniu. Visų tyrimų rezultatai rodo, jog, skiriant trigubą terapiją, sumažèja LOPL paūmėjimų dažnis, pagereja plaučių funkcija ir su sveikata susijusi gyvenimo kokybė nesukeliant žalos sveikatai. Triguba terapija yra veiksminga gydant LOPL sergančius pacientus, kuriems būdingi nuolatiniai respiraciniai simptomai ir ligos paūmejjimai su nedidele šalutinių poveikių rizika. Be to, tyrimų rezultatai rodo ilgesni pacientų išgyvenamumą, o pastaraisiais metais tiriamas ir trigubos terapijos poveikis LOPL sergantiesiems, kuriems būdingi nuolatiniai respiraciniai simptomai, tačiau ligos paūmejjimo rizika maža.

Reikšminiai žodžiai: lètinè obstrukcinè plaučių liga, triguba terapija, įkvepiamieji gliukokortikoidai, veiksmingumas, saugumas. Summary. Recently, two "fixed triple" single-inhaler combinations of an inhaled corticosteroid (ICS), a long-acting $\beta_{2}$-agonist (LABA), and a long-acting muscarinic antagonist (LAMA) have become available for patients with chronic obstructive pulmonary disease (COPD). This review provides evidence from clinical trials on the efficacy and safety of triple therapy. Of the five main fixed triple studies completed so far, three (TRILOGY, TRINITY and TRIBUTE) evaluated the efficacy and safety of an extrafine formulation of beclometasone dipropionate, formoterol fumarate, and glycopyrronium; the other two studies (FULFIL and IMPACT) evaluated fluticasone furoate, vilanterol, and umeclidinium. Results of all clinical trials showed that triple therapy decreased the risk of exacerbations and improved lung function and health status, with a favourable benefit-to-harm ratio. The evidence suggests that triple therapy is the most effective treatment in symptomatic patients with COPD at risk of exacerbations, with marginal if any risk of side effects. Furthermore, triple therapy showed a promising signal in terms of improved survival. Ongoing studies are examining the role of triple therapy in less severe symptomatic patients with COPD.
\end{abstract}

Keywords: chronic obstructive pulmonary disease, triple therapy, inhaled corticosteroids, efficiency, safety.

\section{IVADAS}

Dabartinèse Visuotinès obstrukcinès plaučių ligos iniciatyvos (angl. the Global Initiative for Chronic Obstructive Lung Disease, GOLD) gydymo rekomendacijose pateikiama, jog farmakologinis lètinès obstrukcinès plaučių ligos (LOPL) gydymas turètų būti individualizuotas ir pagrịstas vienos veikliosios medžiagos arba skirtingų veikliųjų medžiagų derinio skyrimu. Pagrindinè farmakologinè vaistų grupé, gydant LOPL, yra bronchus plečiamieji vaistai: ilgo veikimo $\beta_{2}$ agonistai (IVBA) ir ilgo veikimo muskarino receptorių blokatoriai (IVMB). GOLD iniciatyva rekomenduoja LOPL gydymą papildyti įkvepiamaisiais gliukokortikoidais (iGK) ir skirti trigubą terapiją tiems pacientams, kuriems būdingi nuolatiniai respiraciniai simptomai, ne rečiau nei du kartus per metus pasireiškia ligos paūmèjimai arba per paskutinius metus buvo bent vienas ligos paūmèjimas, gydytas stacionare. Naujausi klinikinių tyrimų rezultatai rodo trigubos terapijos naudą ne tik mažinant paūmèjimų dažnị, bet gerinant ir plaučių funkciją, su sveikata susijusią gyvenimo kokybę, mažinant greito veikimo bronchus plečiamųjų vaistinių preparatų poreikį, o svarbiausia mirties riziką, lyginant su monoterapija IVMB.

\section{TRIJUৃ VEIKLIŲJŲ MEDŽIAGŲ DERINIAI VIENAME INHALIATORIUJE}

Straipsnyje apžvelgiami klinikiniai tyrimai, kurių metu tirti du skirtingi vaistiniai preparatai, talpinantys iGK/IVBA/IVMB derinị viename inhaliatoriuje. Vieną vaistą sudaro beklometazono dipropionatas, formoterolio fumaratas ir glikopironio bromidas (BDF/FF/G), kitą - flutikazono furoatas, vilanterolis ir umeklidinas (FLF/VI/UMEC). BDF/FF/G skiriamas per aerozolini inhaliatorių, ịkvejpimui sukuriantị itin smulkių dalelių (vidutinis aerodinaminis skersmuo apie 2 mikrometrus) dulksną. FLF/VI/UMEC veikliụjų medžiagu derinys skiriamas sausų miltelių pavidalu. Abu vaistai 


\section{Farmakoterapija}

gali būti skiriami pacientams, sergantiems vidutinio sunkumo arba sunkia LOPL, kai gydymas iGK/IVBA arba IVBA/IVMB nepakankamas.

\section{BDF/FF/G DERINYS VIENAME INHALIATORIUJE: TRILOGY, TRINITY IR TRIBUTE KLINIKINIU TYRIMU DUOMENYS}

TRILOGY, TRINITY ir TRIBUTE - tai trečios fazès, 12 mèn. trukmès, atsitiktinių imčių, paralelinių grupių, dvigubai akli klinikiniai tyrimai, kuriuose dalyvavo 2529 LOPL sergantys pacientai su nustatyta sunkia arba labai sunkia bronchų obstrukcija (forsuoto iškvèpimo tūris per 1 sek., $\mathrm{FEV}_{1}$, po bronchus plečiamojo vaisto $<50$ proc.). Visi tiriamieji turèjo nuolatinius respiracinius simptomus (pagal LOPL vertinimo testą (angl. COPD assesment test, CAT) surinko ne mažiau nei 10 balų) ir per pastaruosius metus patyrè bent vieną vidutinio sunkumo arba sunkų ligos paūmèjimą (1 lentelè). I tyrimus neittraukti asmenys, kurie per paskutinius metus iki tyrimo pradžios buvo gydyti triguba terapija. Gauti tyrimų rezultatai parodè, kad, skiriant trigubą terapiją, pagereja $\mathrm{FEV}_{1}$ ir su sveikata susijusi gyvenimo kokybė (naudotas Šv. Jurgio kvèpavimo klausimynas, angl. the St. Georges Respiratory Questionnaire, SGRQ), sumažeja vidutinio sunkumo arba sunkių LOPL paūmejjimų dažnis, lyginant su monoterapija IVMB arba iGK/IVBA ir IVBA/IVMB deriniais.

TRINITY klinikiniame tyrime BDF/FF/G veikliųuc medžiagų derinys viename inhaliatoriuje buvo veiksmingesnis nei monoterapija tiotropiu ir ne mažiau veiksmingas nei skiriant $\mathrm{BDF} / \mathrm{FF}$ ir tiotropi. Rezultatai vertinti tiek pagal $\mathrm{FEV}_{1}$ reikšmę, tiek pagal vidutinio sunkumo arba sunkių ligos paūmèjimų dažnį.

TRILOGY tyrimo rezultatai parodè, jog, skiriant trigubą terapiją BDF/FF/G, lyginant su gydymu BDF/FF, reikšmingai prailgèja laikotarpis iki pirmo ligos sąlygoto būklès pablogejjimo, kuris apibrèžiamas $\mathrm{FEV}_{1}$ sumažèjimu ne mažiau $100 \mathrm{ml}$ nuo pradinès reikšmės, Šv. Jurgio kvėpavimo klausimyno balo sumažejimu ne mažiau kaip 4 balais nuo pradinio įvertinimo, laikino dusulio indekso (angl. Transition Dyspnea Index, TDI) sumažèjimu ne mažiau kaip 1 balas nuo pradinio ivertinimo, vidutinio sunkumo arba sunkiu LOPL paūmèjimu. TRILOGY klinikinio tyrimo pacientams, pagal GOLD iniciatyvą atitinkantiems $\mathrm{B}$ grupę, triguba terapija $\mathrm{BDF} /$ FF/G sumažino vidutinio sunkumo ir sunkių paūméjimų dažnį, lyginant su gydymu BDF/FF. Šie rezultatai atitinka TRINITY tyrimo rezultatus, kurie parodé, jog triguba terapija BDP/FF/G prailgina laikotarpi iki pirmo ligos sąlygoto būklès pablogèjimo ir sumažina vidutinio sunkumo arba sunkių LOPL paūmejjimų dažnį, lyginant su tiotropiu pacientams, pagal GOLD iniciatyvą atitinkantiems B grupę.

TRIBUTE tyrimo metu buvo patvirtintas trigubos terapijos BDF/FF/G teigiamas naudos ir žalos santykis (įskaitant pneumonijų pasireiškimo dažnị), lyginant su gydymu dviem bronchus plečiamaisiais vaistais. Buvo suretinti vidutinio sunkumo ir sunkūs LOPL paūmejjimai, kartu išlaikant panašu pneumonijos atvejų dažnị (pav.).

\section{FLF/VI/UMEC DERINYS VIENAME INHALIATORIUJE: FULFIL IR IMPACT KLINIKINIŲ TYRIMUQ DUOMENYS}

FULFIL ir IMPACT yra pagrindiniai klinikiniai tyrimai, kurių rezultatai rodo trigubos terapijos FLF/VI/ UMEC pranašumą, lyginant su ịprastu LOPL gydymu. Skiriant šị veikliųjų medžiagų derinị viename inhaliatoriuje, pagerejja plaučių funkcija ir su sveikata susijusi gyvenimo kokybè bei sumažèja LOPL paūmèjimų dažnis. FULFIL ir IMPACT tyrimuose dalyvavo 5062 atsitiktiniu būdu atrinkti LOPL sergantys pacientai, kuriems būdingi nuolatiniai respiraciniai simptomai (CAT ne mažiau 10 balu), tačiau kiti abieju tyrimu ịtraukimo kriterijai šiek tiek skyrèsi (2 lentelè).

FULFILL tyrime lygintas trigubos terapijos FLF/VI/ UMEC veiksmingumas su budezonido ir formoterolio fumarato (BUD/FF) deriniu pacientams, turintiems sunkią bronchų obstrukciją, mažą paūmėjimų riziką bei sergantiems vidutinio sunkumo bronchų obstrukcija ir turintiems didelę paūmèjimų riziką. Šis tyrimas parode trigubos terapijos pranašumą gerinant plaučių funkciją ir su sveikata susijusią gyvenimo kokybę.

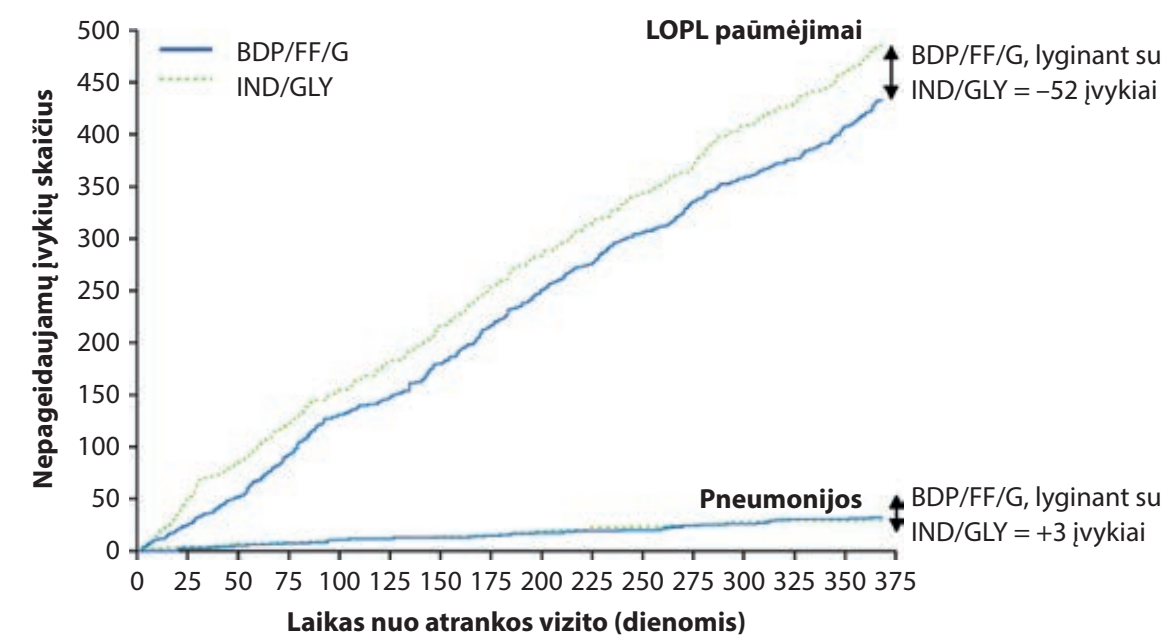

Pav. Naudos ir žalos santykis pagal lètinès obstrukcinès plaučių ligos paūmèjimų ir pneumonijų skaičiu 


\section{Farmakoterapija}

1 lentelè. Klinikinių tyrimų TRILOGY, TRINITY ir TRIBUTE apžvalga

\begin{tabular}{|c|c|c|c|c|c|c|c|}
\hline \multirow[t]{2}{*}{ Gydymo grupès } & \multicolumn{2}{|c|}{ TRILOGY } & \multicolumn{3}{|c|}{ TRINITY } & \multicolumn{2}{|c|}{ TRIBUTE } \\
\hline & $\begin{array}{l}\text { BDF/FF/G } \\
(n=687)\end{array}$ & $\begin{array}{l}\text { BDF/FF } \\
(n=680)\end{array}$ & $\begin{array}{l}\text { BDF/FF/G } \\
(n=1077)\end{array}$ & $\begin{array}{l}\text { Tiotropis } \\
(\mathrm{n}=1074)\end{array}$ & $\begin{array}{l}\text { BDF/FF + } \\
\text { tiotropis } \\
(\mathbf{n}=538)\end{array}$ & $\begin{array}{l}\text { BDF/FF/G } \\
(n=764)\end{array}$ & $\begin{array}{l}\text { IND/GLY } \\
(n=768)\end{array}$ \\
\hline Tyrimo trukmè & \multicolumn{2}{|c|}{12 mèn. } & \multicolumn{3}{|c|}{12 mèn. } & \multicolumn{2}{|c|}{12 mèn. } \\
\hline Pagrindiniai įtraukimo į tyrimą kriterijai & \multicolumn{7}{|c|}{$\begin{array}{l}\text { - } \mathrm{FEV}_{1}<50 \text { proc. } \\
\text { - } \geq 1 \text { vidutinio sunkumo arba sunkus paūmèjimas per pastaruosius } 12 \text { mèn. } \\
\text { - } \mathrm{CAT} \geq 10 \\
\text { - } \mathrm{iGK/IVBA} \text {, iGK/IVMA, IVMA/IVBA arba IVMA naudojimas } \geq 2 \text { mèn. prieš atranką } \\
\text { *Papildomas TRILOGY tyrimo itraukimo kriterijus - pradinis dusulio indeksas } \geq 10 \text { balu }\end{array}$} \\
\hline Vidutinè FEV ${ }_{1}$ reikšmè, proc. (SN) & $36,9(8,4)$ & $36,2(8,6)$ & $36,6(8,3)$ & $36,6(8,1)$ & $36,7(8,3)$ & $36,4(8,0)$ & $36,4(8,1)$ \\
\hline \multicolumn{8}{|c|}{ FEV ${ }_{1}$ pasiskirstymas proc. pagal būtinaji dydi } \\
\hline 30 proc. iki $<50$ proc. & 77,0 & 77,0 & 79,0 & 79,0 & 79,0 & 80,0 & 79,0 \\
\hline$<30$ proc. & 23,0 & 23,0 & 21,0 & 21,0 & 21,0 & 20,0 & 21,0 \\
\hline Paūmèjimų dažnis (ribos) & $1,2(1-5)$ & $1,2(1-6)$ & $1,3(1-11)$ & $1,3(1-5)$ & $1,2(1-7)$ & $1,2(1-6)$ & $1,2(1-4)$ \\
\hline CAT vidurkis (SN) & $20,8(5,9)$ & $20,8(5,7)$ & $21,5(5,8)$ & $21,6(5,8)$ & $21,7(6,0)$ & Nenurodyta & \\
\hline \multicolumn{8}{|l|}{ REZULTATAI } \\
\hline \multicolumn{8}{|l|}{ Paūmèjimų dažnis } \\
\hline Vidutinio sunkumo ir sunkūs & 0,41 & 0,53 & 0,46 & 0,57 & 0,45 & 0,50 & 0,59 \\
\hline Dažnio santykis (95 proc. PI) & \multicolumn{2}{|c|}{$0,77(0,65-0,92) ; p=0,005$} & \multicolumn{3}{|c|}{$\begin{array}{c}\text { BDF/FF/G, lyginant su tiotropiu: } \\
0,8(0,69-0,92) ; p=0,0025 \\
\text { BDF/FF/G, lyginant su BDF/FF+ } \\
\text { tiotropiu: } 1,01(0,85-1,21) ; p=0,89\end{array}$} & \multicolumn{2}{|c|}{$\begin{array}{c}0,848(0,723-0,995) \\
p=0,043\end{array}$} \\
\hline Sunkūs & 0,12 & 0,14 & 0,07 & 0,10 & 0,06 & 0,07 & 0,09 \\
\hline Dažnio santykis (95 proc. PI) & \multicolumn{2}{|c|}{ Nenurodyta } & \multicolumn{3}{|c|}{$\begin{array}{c}\text { BDP/FF/G, lyginant su tiotropiu: } \\
0,68(0,50-0,94) ; p=0,0174 \\
\text { BDP/FF/G, lyginant su BDF/FF + } \\
\text { tiotropiu: } 1,18(0,77-1,80) ; p=0,45\end{array}$} & \multicolumn{2}{|c|}{$\begin{array}{c}0,787(0,551-1,125) \\
p=0,189\end{array}$} \\
\hline \multicolumn{8}{|l|}{$\mathrm{FEV}_{1}$ pokytis (I) nuo pradinio dydžio } \\
\hline 26-tą savaitę & 0,082 & 0,001 & \multicolumn{3}{|c|}{ Nenurodyta } & Nenurodyta & Nenurodyta \\
\hline Vidurkiu skirtumas (95 proc. PI) & \multicolumn{2}{|c|}{$\begin{array}{c}0,081(0,052-0,109) \\
p<0,01\end{array}$} & \multicolumn{3}{|c|}{$\begin{array}{c}\text { BDP/FF/G, lyginant su tiotropiu: } \\
p<0,001 \\
\text { BDP/FF/G, lyginant su BDF/FF + } \\
\text { tiotropiu: } p=^{*}\end{array}$} & \multicolumn{2}{|c|}{0,$02 ; p=*$} \\
\hline 52 savaitès & 0,071 & 0,008 & 0,082 & 0,021 & 0,085 & Nenurodyta & Nenurodyta \\
\hline Vidurkiu skirtumas (95 proc. PI) & \multicolumn{2}{|c|}{$\begin{array}{l}0,063(0,032-0,094) \\
p<0,001\end{array}$} & \multicolumn{3}{|c|}{$\begin{array}{c}\text { BDP/FF/G, lyginant su tiotropiu: } \\
0,061(0,037-0,086) ; \mathrm{p}<0,0001 \\
\text { BDP/FF/G, lyginant su BDP/FF + } \\
\text { tiotropiu: }-0,003(-0,033 \text { iki } 0,027) \\
\text { p }=0,85\end{array}$} & \multicolumn{2}{|c|}{0,$019 ; p=*$} \\
\hline $\begin{array}{l}\text { Pacientu skaičius su nustatyta pneumonija, } \\
\text { n (proc.) }\end{array}$ & $23(3,0)$ & $18(3,0)$ & $28(3,0)$ & $19(2,0)$ & $12(2,0)$ & $28(4,0)$ & $27(4,0)$ \\
\hline Mirtingumas, proc. (nuo visų priežasčių) & 2,2 & 2,4 & 1,9 & 2,7 & 1,5 & 2,1 & 2,7 \\
\hline Rizikos santykis (95 proc. PI) & \multicolumn{7}{|c|}{$\begin{array}{l}\text { BDP/FF/G, BDF/FF ir BDF/FF+tiotropis ( } n=3745) \text {, lyginant su tiotropiu ir IND/GLY }(n=1844) \text { : } \\
0,71(0,5-1,02) ; p=0,066 \\
\text { BDP/FF/G }(n=2528) \text {, lyginant su tiotropiu ir IND/GLY }(n=1844): 0,72(0,49-1,06) ; p=0,096\end{array}$} \\
\hline
\end{tabular}

BDF/FF - beklometazono dipropionatas, formoterolio fumaratas; BDF/FF/G - beklometazono dipropionatas, formoterolio fumaratas ir glikopironiumas; BUD/FF - budezonidas ir formoterolio fumaratas; CAT-LOPL vertinimo testas; FEV 1 - forsuoto iškvepimo tūris per 1 sek.; FLF/VI - flutikazono furoatas ir vilanterolis; FLF/VI/UMEC - flutikazono furoatas, vilanterolis ir umeklidinas; iGK - inhaliuojamieji gliukokortikoidai; IND/GLY - indakaterolis ir glikopironiumas; IVBA - ilgo veikimo $\beta_{2}$ agonistai; IVMB - ilgo veikimo muskarino receptorių blokatoriai; PI - pasikliautinasis intervalas; SN - standartinis nuokrypis; UMEC/VI - umeklidinas ir vilanterolis. *Statistiškai nereikšminga.

IMPACT klinikiniame tyrime trigubos terapijos FLF/ VI/UMEC derinio veiksmingumas lygintas su FLF/VI ir UMEC/VI deriniais (naudojant vienodus inhaliatorius ELLIPTA). Tyrimo rezultatai parodè pagerejusią plaučių funkciją ir su sveikata susijusią gyvenimo kokybę bei sumažèjusị ligos paūmèjimo dažnį, skiriant trigubą terapiją ir lyginant su dviejų vaistų deriniais. Didelè IMPACT tyrimo imtis (iš viso atsitiktine tvarka ịtraukta daugiau nei 10000 pacientų) leidžia apibendrinti, jog mirtingu- mas nuo visų priežasčių, sergant LOPL, yra mažesnis skiriant trigubą terapiją arba FLF/VI nei dviejų veikliujų medžiagų derinius - IVBA/IVMB arba UMEC/VI.

\section{PNEUMONIJOS RIZIKA GYDANT TRIGUBA TERAPIJA}

Viena iš trijų farmakologinių vaistų grupių, itrauktų $i$ trigubos terapijos inhaliatoriaus sudèti, yra iGK. Skiriant ši gydymą, tikètina didesnè infekcinių ligų rizika, 
Farmakoterapija

2 lentelè. Klinikinių tyrimų FULFIL ir IMPACT apžvalga

\begin{tabular}{|c|c|c|c|c|c|}
\hline \multirow[t]{2}{*}{ Gydymo grupès } & \multicolumn{2}{|c|}{ FULFIL } & \multicolumn{3}{|c|}{ IMPACT } \\
\hline & $\begin{array}{l}\text { FLF/VI/UMEC } \\
(\mathrm{n}=911)\end{array}$ & $\begin{array}{l}\text { BUD/FF } \\
(\mathrm{n}=\mathbf{8 9 9})\end{array}$ & $\begin{array}{l}\text { FLF/VI/UMEC } \\
(\mathrm{n}=4151)\end{array}$ & $\begin{array}{l}\text { FLF/VI } \\
(n=4134)\end{array}$ & $\begin{array}{l}\text { UMEC/VI } \\
(\mathrm{n}=2070)\end{array}$ \\
\hline Tyrimo trukmè & \multicolumn{2}{|c|}{$\begin{array}{c}24 \text { savaitės, pratęsiant } \\
\text { iki } 52 \text { savaičių }\end{array}$} & \multicolumn{3}{|c|}{52 savaitès } \\
\hline Pagrindiniai įtraukimo į tyrimą kriterijai & \multicolumn{2}{|c|}{$\begin{array}{l}\text { CAT } \geq 10 \text { ir: } \\
\text { - } \mathrm{FEV}_{1}<50 \text { proc. } \\
\text { arba } \\
\text { - } \mathrm{FEV}_{1} \geq 50 \text { proc., bet }<80 \text { proc. ir } \\
\geq 2 \text { vidutinio sunkumo paūmèji- } \\
\text { mai arba } \geq 1 \text { sunkus paūmèjimas } \\
\text { per pastaruosius metus }\end{array}$} & \multicolumn{3}{|c|}{$\begin{array}{l}\text { CAT } \geq 10 \text { ir: } \\
\text { - } \mathrm{FEV}_{1}<50 \text { proc. ir } \geq 1 \text { vidutinio sunkumo arba } \\
\text { sunkus paūmèjimas per pastaruosius metus } \\
\text { arba } \\
\text { - } \mathrm{FEV}_{1} \geq 50 \text { proc. iki }<80 \text { proc. ir } \geq 2 \text { vidutinio sunku- } \\
\text { mo paūmèjimai arba } \geq 1 \text { sunkus paūmèjimas per } \\
\text { pastaruosius vienerius metus }\end{array}$} \\
\hline Vidutinè FEV 1 reikšmè, proc. (SN) & $45,5(13,0)$ & $45,1(13,6)$ & $45,7(15,0)$ & $45,5(14,8)$ & $45,4(1,7)$ \\
\hline \multicolumn{6}{|l|}{ FEV 1 pasiskirstymas proc. pagal būtinajị dydị } \\
\hline$\geq 80$ proc. & Nenurodyta & Nenurodyta & $<1,0$ & $<1,0$ & $<1,0$ \\
\hline 50 proc. iki $<80$ proc. & Nenurodyta & Nenurodyta & 37,0 & 35,0 & 35,0 \\
\hline 30 proc. iki $<50$ proc. & Nenurodyta & Nenurodyta & 47,0 & 49,0 & 49,0 \\
\hline$<30$ proc. & Nenurodyta & Nenurodyta & 16,0 & 15,0 & 15,0 \\
\hline CAT vidurkis (SN) & Nenurodyta & Nenurodyta & $20,1(6,1)$ & $20,1(6,1)$ & $20,2(6,2)$ \\
\hline \multicolumn{6}{|l|}{ REZULTATAI } \\
\hline \multicolumn{6}{|l|}{ Paūmèjimų dažnis } \\
\hline Vidutinio sunkumo ir sunkūs & 0,22 & 0,34 & 0,91 & 1,07 & 1,21 \\
\hline Dažnio santykis (95 proc. PI) & \multicolumn{2}{|c|}{$0,65(0,49-0,86) ; p=0,002$} & \multicolumn{3}{|c|}{$\begin{array}{c}\text { FLF/UMEC/VI, lyginant su FLF/VI: } \\
\text { 0,85 }(0,8-0,9) ; p<0,001 \\
\text { FLF/UMEC/VI, lyginant su UMEC/VI: } \\
0,75(0,7-0,81) ; p<0,001\end{array}$} \\
\hline Sunkūs & $\begin{array}{c}1,0 \text { proc. } \\
\text { per } 24 \text { sav. }\end{array}$ & $\begin{array}{c}2,0 \text { proc. } \\
\text { per } 24 \text { sav. }\end{array}$ & 0,13 & 0,15 & 0,19 \\
\hline Dažnio santykis (95 proc. PI) & \multicolumn{2}{|c|}{ Nenurodyta } & \multicolumn{3}{|c|}{$\begin{array}{c}\text { FLF/UMEC/VI, lyginant su FLF/VI: } \\
0,87(0,76-1,01) ; p=0,06 \\
\text { FLF/UMEC/VI, lyginant su UMEC/VI: } \\
0,66(0,56-0,78) ; p<0,001\end{array}$} \\
\hline \multicolumn{6}{|l|}{ FEV $_{1}$ pokytis (I) nuo pradinio dydžio } \\
\hline 24-ta savaitè & 0,142 & $-0,029$ & Nenurodyta & Nenurodyta & Nenurodyta \\
\hline Vidurkių skirtumas (95 proc. PI) & \multicolumn{2}{|c|}{$0,171(0,148-0,194) ; p<0,001$} & \multicolumn{3}{|c|}{ Nenurodyta } \\
\hline 52-ta savaitè & 0,126 & $-0,053$ & 0,094 & $-0,003$ & 0,040 \\
\hline Vidurkių skirtumas (95 proc. PI) & \multicolumn{2}{|c|}{$0,179(0,131-0,226) ; p<0,001$} & \multicolumn{3}{|c|}{$\begin{array}{c}\text { FLF/UMEC/VI, lyginant su FLF/VI: } \\
\text { 0,097 (0,085-0,109); } \mathrm{p}<0,001 \\
\text { FLF/UMEC/VI, lyginant su UMEC/VI: } \\
\text { 0,054 (0,039-0,069); } \mathrm{p}<0,001\end{array}$} \\
\hline $\begin{array}{l}\text { Pacientų skaičius, kuriems nustatyta pneumonija, } \\
\mathrm{n} \text { (proc.) }\end{array}$ & $\begin{array}{l}20(2,2) \\
\text { per } 24 \text { sav. }\end{array}$ & \begin{tabular}{|c|}
$7(0,8)$ \\
per 24 sav.
\end{tabular} & $317(8,0)$ & $292(7,0)$ & $97(5,0)$ \\
\hline Mirtingumas, proc. (nuo visų priežasčių) & \multicolumn{2}{|c|}{ Nenurodyta } & 1,20 proc. & 1,19 proc. & 1,88 proc. \\
\hline
\end{tabular}

BDF/FF - beklometazono dipropionatas, formoterolio fumaratas; BDF/FF/G - beklometazono dipropionatas, formoterolio fumaratas ir glikopironiumas; BUD/FF - budezonidas ir formoterolio fumaratas; CAT-LOPL vertinimo testas; FEV 1 - iškvepiamojo oro tūris per 1 sek.; FLF/VI - flutikazono furoatas ir vilanterolis; FLF/VI/UMEC - flutikazono furoatas, vilanterolis ir umeklidinas; iGK - inhaliuojamieji gliukokortikoidai; IND/GLY - indakaterolis ir glikopironiumas; IVBA - ilgo veikimo $\beta_{2}$ agonistai; IVMB - ilgo veikimo muskarino receptorių blokatoriai; PI - pasikliautinasis intervalas; $\mathrm{SN}$ - standartinis nuokrypis; $\mathrm{UMEC} / \mathrm{VI}$ - umeklidinas ir vilanterolis.

lyginant su bronchų plečiamaisiais vaistais. TRILOGY klinikinio tyrimo duomenimis, abiejose gydymo grupèse, kuriose skirti vaistų deriniai su iGK (BDF/FF/G ir $\mathrm{BDF} / \mathrm{FF})$, pneumonijos rizika buvo panaši (3,0 proc.). TRINITY tyrimo duomenimis, panašus pneumonijos dažnis nustatytas trijose gydymo grupèse: $\mathrm{BDF} / \mathrm{FF} / \mathrm{G}$, tiotropio, BDF/FF/tiotropio (atitinkamai - 3,0 proc., 2,0 proc., 2,0 proc.). Panašūs rezultatai gauti ir TRIBUTE tyrime, kuriame penumonijų dažnis, gydant BDP/ FF/G arba indakaterolio ir glikopironio deriniu (IND/ GLY), nesiskyrè (pasireiškè 4 proc. tiriamųjų abiejose grupèse). Šiems rezultatams prieštarauja FLAME tyrimo duomenys, kurie rodo, jog, gydymui skiriant flutikazono propionato ir salmeterolio derinị (FLP/ SAL), nustatytas statistiškai reikšmingas pneumonijų dažnio padidejimas, lyginant su gydymu IND/GLY (atitinkamai $-4,8$ ir 3,2 proc.; $\mathrm{p}=0,002$ ). FULFILL tyrimo metu nustatyta didesnè pneumonijos rizika pacientams, gydytiems FLF/UMEC/VI nei BUD/FF (atitinkamai 2,2 ir 0,8 proc.). Panašūs rezultatai gauti atliekant ir IMPACT tyrimą: gydant FLF/VI/UMEC pneumonijų dažnis statistiškai reikšmingai buvo di- 


\section{Farmakoterapija}

desnis, lyginant su UMEC/VI (atitinkamai - 8,0 ir 5,0 proc.; $\mathrm{p}=0,001)$, ir panašus kaip pacientams, gydytiems FLF/VI ( 7,0 proc.; $\mathrm{p}=0,85)$.

\section{TRIGUBA TERAPIJA IR IŠGYVENAMUMAS}

Anksčiau aprašytų klinikinių tyrimų tikslas buvo ivvertinti trigubos terapijos veiksmingumą ir saugumą, tačiau gauti rezultatai taip pat žada ilgesnị LOPL sergančių ir triguba terapija gydomų pacientų išgyvenamumą. IMPACT tyrimo rezultatai parode statistiškai reikšmingus išgyvenamumo skirtumus, lyginant gydymą triguba terapija su gydymu dviem bronchus plečiamaisiais vaistais, ir mažesnius, tačiau taip pat reikšmingus skirtumus trigubą terapiją lyginant su iGK/IVBA deriniu. Tikimasi, kad ateityje klinikiniai tyrimai bus skirti pacientų, gydomų triguba terapija, išgyvenamumui įvertinti. Be to, svarbu atkreipti demesị, kad tinkamas gretutinių ligų gydymas, tokių kaip lètinis širdies nepakankamumas, išeminè širdies liga, insultas, cukrinis diabetas arba pirminè arterinè hipertenzija, yra svarbūs su sveikata susijusiai gyvenimo kokybei ir išgyvenamumui gerinti.

\section{GYDYMO TRIGUBA TERAPIJA TIKSLINE் GRUPE்}

Abu veikliųjų medžiagų deriniai (BDP/FF/GB ir FLF/VI/UMEK) yra patvirtinti palaikomajam vidutinio sunkumo arba sunkios LOPL gydymui, kai iGK ir IVBA nepakankamai veiksmingi. Vèliau šių vaistų indikacijos papildytos, todèl triguba terapija tapo prieinama didesniam pacientų skaičiui. Nuo $2019 \mathrm{~m}$. sausio $23 \mathrm{~d}$. gydymas FLF/VI/UMEK (TRIMBOW) skiriamas ir LOPL sergantiems pacientams, kuriems IVBA ir IVMB nepakankamai veiksmingi. Pagal GOLD iniciatyvą triguba terapija rekomenduojama D grupès pacientams, kuriems pasireiškia ligos paūmejjimai, nepaisant skiriamo gydymo dviem ilgo veikimo bronchus plečiamaisiais vaistais (IVBA ir IVMB) arba iGK ir IVBA. Trigubos terapijos veiksmingumas tirtas ne tik GOLD D grupès pacientams, bet ir daliai B grupés pacientų. Papildomos TRILOGY ir TRINITY tyrimu post hoc analizès metu įrodyta trigubos terapijos nauda daliai $\mathrm{B}$ grupès sergančiųju LOPL, kuriems anamnezèje buvęs vienas vidutinio sunkumo paūmèjimas.

\section{APIBENDRINIMAS}

Naujausi klinikiniai tyrimai parode, kad iGK kartu su IVBA ir IVMB viename inhaliatoriuje yra veiksmingi gydant sergančiuosius vidutinio sunkumo arba sunkia LOPL, ypač su pasikartojančiais ligos paūmejjimais. Trigubos terapijos veiksmingumą lyginant su gydymu IVMB arba iGK/IVBA, arba IVMB/IVBA deriniais, irodyta, kad triguba terapija ne tik pagerina plaučių funkciją ir su sveikata susijusią gyvenimo kokybę, bet ir sumažina greito veikimo bronchų plečiamųjų vaistinių preparatų poreikị bei paūmèjimų dažnị. 